\title{
Investigation of the Effects of Team Coaching, Performance Feedback, and Collective Efficacy on Small Group Performance
}

Rachael Nichole Martinez

Loyola University Chicago

Follow this and additional works at: https://ecommons.luc.edu/luc_theses

Part of the Social Psychology Commons

\section{Recommended Citation}

Martinez, Rachael Nichole, "Investigation of the Effects of Team Coaching, Performance Feedback, and Collective Efficacy on Small Group Performance" (2010). Master's Theses. 538.

https://ecommons.luc.edu/luc_theses/538

This Thesis is brought to you for free and open access by the Theses and Dissertations at Loyola eCommons. It has been accepted for inclusion in Master's Theses by an authorized administrator of Loyola eCommons. For more information, please contact ecommons@luc.edu. (c) $($ ) $(9)$

This work is licensed under a Creative Commons Attribution-Noncommercial-No Derivative Works 3.0 License. Copyright (c) 2010 Rachael Nichole Martinez 
LOYOLA UNIVERSITY CHICAGO

INVESTIGATION OF THE EFFECTS OF TEAM COACHING, PERFORMANCE FEEDBACK, AND COLLECTIVE EFFICACY

ON SMALL GROUP PERFORMANCE

\author{
A THESIS SUBMITTED TO \\ THE FACULTY OF THE GRADUATE SCHOOL \\ IN CANDIDACY FOR THE DEGREE OF \\ MASTER OF ARTS
}

PROGRAM IN APPLIED SOCIAL PSYCHOLOGY

BY

RACHAEL MARTINEZ

CHICAGO, ILLINOIS

AUGUST 2010 



\section{LIST OF TABLES}

Table

Page

1. Means of group performance on Task 1 and Task 2 across coaching conditions

2. Percentage of groups who utilized each strategy for Task 1 and Task 2

3. Percentage of groups (out of all groups) that showed strategy improvement/maintenance within Task 1, between Tasks 1 and 2, and within Task 2

4. Means of group performance on Task 1 for groups who received negative feedback across coaching conditions and strategies

5. Means of group performance on Task 1 for groups who received positive feedback across coaching conditions and strategies

6. Means of group performance on Task 2 across coaching and feedback conditions

7. Means of group performance on Task 2 across coaching conditions and symptom sharing strategies

8. Correlations between independent and dependent variables 


\section{LIST OF FIGURES}

Figure

Page

1. Means of group performance across coaching conditions and time

2. Group cohesiveness over time, across coaching conditions

3. Group goals over time, across coaching conditions 


\begin{abstract}
Research has demonstrated that there are a variety of factors that influence group performance such as team coaching, feedback, and collective efficacy. A study was conducted to determine whether consultative team coaching improves performance and at what point — beginning or middle — it is most beneficial to the team. One hundred eleven dyads, comprised of 222 students, participated in this study. The dyads performed a task twice in which they were given team coaching before the first attempt, after the first attempt, or not at all. In addition, feedback was manipulated such that teams received positive or negative feedback after their first attempt of the task. Each participant filled out questionnaires assessing collective efficacy, group goals, and group cohesiveness at three different times — beginning, middle, and end - over the course of the study. Results indicated there was a significant main effect of team coaching, however it was due to superior performance by groups in the no coaching condition during the first performance period. In addition, there were significant Time $\mathrm{x}$ Coaching interactions predicting group cohesiveness and group goals. Overall, collective efficacy was positively related to group goals and group cohesiveness. Furthermore, collective efficacy was positively related to group performance such that group performance influenced the team's collective efficacy. Moreover, team coaching led to strategy improvement. Limitations of current study and implications for further research are discussed.
\end{abstract}




\section{LITERATURE REVIEW}

Organizations are composed of many individuals, and often times, these individuals must work together on a variety of tasks. Work teams (e.g., marketing teams, sales teams, etc.) are prevalent in many, if not most, organizations, and the importance of team work and members has taken on a greater role in organizational performance. Because teams are an integral part of many organizations, understanding team performance and how it can be improved has become increasingly important to organizations. Team coaching has been recommended as one of the potential ways in which organizations can improve team functioning and ultimately team performance. This study will attempt to explore how and when team coaching can be used effectively.

\section{Team Coaching}

Coaches help individuals and groups of individuals, such as teams, carry out a specific task. A coach, or leader, can utilize a variety of different techniques to cultivate team effectiveness, and coaching style varies based on the attention the coach gives to these different techniques. Broadly speaking, team coaching refers to the act of a coach providing leadership to a team. Specifically, Hackman and Wageman (2005) define team coaching as "direct interaction with a team intended to help members make coordinated and task-appropriate use of their collective resources in accomplishing the team's work" (p. 269). According to Hackman and Wageman (2005), among the variety of leadership behaviors available to coaches, team coaching is utilized less than other aspects of team 
leadership. A study conducted by Wageman, Hackman \& Lehman (2004) found that among 268 task-performing teams from 88 organizations, team coaching was ranked as getting the least attention of four categories of leadership behaviors - structuring the team, arranging for resources, helping individual members contribute to the team, and working with the team as a whole (team coaching). The results from their study suggest that leaders underestimate the potential benefits of team coaching, or more likely, that leaders do not know how to provide effective team coaching. Based on past research and theory, Hackman and Wageman (2005) propose a new model of team coaching that identifies the functions, specific times, and conditions under which team coaching will ultimately help teams perform more effectively.

The theory of team coaching proposed by Hackman and Wageman (2005) revolves around three components - the functions that coaching serves for a team, the specific times during the task performance process when coaching is most effective, and the conditions under which team coaching is and is not likely to improve performance. Addressing the first of the three components, there are specific functions that are critical to team performance effectiveness. For the purpose of identifying the most critical functions served by coaches of work teams, Hackman and colleagues highlight three features of group interaction that impact group performance-level of effort of group members, appropriateness of group performance strategies to the task, extent of knowledge and skill of group members (Hackman \& Morris, 1975; Hackman \& Walton, 1986). In other words, these researchers state that team effectiveness is a joint function of these three performance processes. Therefore, a team that adequately fulfills these three 
criteria will be likely to perform better than a team that may leave one or more of these functions unfulfilled. As with other processes, these three performance processes are susceptible to "process loss" (Steiner, 1972) but also present an opportunity for "process gain" (Hackman \& Wageman, 2005), which is where coaching functions come into play. Coaching functions are interventions, made by the coaches, that can inhibit process losses and promote process gains for each of the performance processes (Hackman \& Wageman, 2005). Hackman \& Wageman (2005) break down the coaching functions as such: Coaching that addresses the level of effort of group members is motivational, coaching that addresses the appropriateness of group performance strategies is consultative, and coaching that addresses the knowledge and skill of the group members is educational (Hackman \& Wageman, 2005). Unlike past theories and models developed about team coaching, the team coaching model proposed by Hackman and Wageman (2005) addresses a team's task performance processes rather than members' interpersonal relationships. Moreover, Hackman and Wageman (2005) argue that performance drives interpersonal processes rather than vice versa. In addition, research that has explicitly compared task-focused coaching and interpersonally focused interventions has found the former to be more beneficial to task teams (Kernaghan \& Cooke, 1990; Woolley, 1998), which leads to the first proposition of the team coaching model— "coaching interventions that focus specifically on team effort, strategy, and knowledge and skill facilitate team effectiveness more than do interventions that focus on members' interpersonal relationships" (Hackman \& Wageman, 2005, p. 274). 
The second component of the team coaching model addresses the specific times during the task performance process when coaching is the most effective. Here, Hackman and Wageman (2005) claim that coaching interventions do not depend solely on the focus - team effort, strategy, and knowledge and skill—but also on the time during the task process when they are made. In the past, theories on group life cycles have generally treated group development as following a series of stages (e.g., Tuckman's “forming-storming-norming-performing” model, 1965). More recently, however, research has found that stage models may not accurately represent group development. For example, Gersick (1988) conducted a field study in which she tracked and observed a number of project teams whose performance periods ranged from days to months. She found that each of the project teams developed a unique approach to its task and stayed with this approach until the midpoint of the group's life cycle (halfway between first meeting and project deadline). At the midpoint, groups changed dramatically. They dropped old patterns of behavior, reconnected with outside supervisors, and assumed a different perspective on the task. From the midpoint until near task completion, groups were focused on completing the task. Gersick's field studies and her laboratory studies replicating these findings support the possibility that the readiness of work teams for coaching interventions changes across their life cycles (Hackman \& Wageman, 2005). Hackman and Wageman (2005) define "readiness for coaching" as the degree to which the issues to be addressed are on the team members' minds at the time of the intervention and the degree to which the team is not preoccupied with other important matters. In other words, coaching interventions are more effective when the team is ready to address 
the issue, and this readiness varies across the team's life cycle. In the team coaching model, Hackman and Wageman (2005) discuss what types of interventions are most effective at the beginnings, midpoints, and ends of work team life cycles.

At the beginning of a work team's life, the group members are getting acquainted with each other, their roles, and the task they will perform. At this point, the group members exhibit a high state of readiness for anything that will reduce their uncertainties and get the team off to a good start. Therefore, a coaching intervention that helps the team get off to a good start can boost the group members' commitment to the team and task, ultimately leading to greater motivation and better performance. Hackman and Wageman (2005) hypothesize that motivational coaching interventions are best when provided at the beginning of a group's life cycle, whereas, interventions that address work strategy (consultative coaching) are not beneficial when teams are just starting out.

According to Hackman and Wageman's (2005) team coaching model, the beginning of a group's life cycle is an inopportune time to discuss team strategies, however the midpoints are not. At the midpoint, the team will have logged some experience with the task, allowing the members to assess what is working well and what is not. In addition, the members are likely to be anxious about the amount of work accomplished and the amount still left to be tackled in the remaining time (Gersick, $1988,1989)$. Because of this, the group's readiness for a strategy-based intervention is high at the midpoint of its life cycle. A study conducted by Woolley (1998) supports this assertion. Woolley (1998) devised a study in which groups were asked to construct a model of a college residence hall from LEGO® blocks, and each group received one of 
two possible coaching interventions at one of two time points (beginning or midpoint). One coaching intervention was meant to improve group members' interpersonal relationships, while the other was meant to provide assistance in formulating a taskappropriate strategy (Woolley, 1998; Hackman \& Wageman, 2005). Woolley’s (1998) findings indicated that the strategy-based coaching intervention was effective at the midpoint yet not at the beginning. In other words, teams need to first experience the task before they are ready to discuss how best to proceed.

The third opportunity for a coaching intervention, as presented in the team coaching model, is at the end, when the work or an important subtask has been completed (Kozlowski, Gully, Salas, \& Cannon-Bowers, 1996). At this point, the team may be more ready than before to reflect back on their performance and learn from their experiences. Because of this, the end is the optimal time for educational coaching interventions (Hackman \& Wageman, 2005; Ellis, Mendel, Nir, \& Davidi, 2002; Blickensderfer, Cannon-Bowers, \& Salas, 1997). When educational coaching interventions come at the end of a team's performance, they can reinforce the team's talent and contribute to learning of individual team members (Hackman \& Wageman, 2005).

As research has shown, competent, well-timed coaching interventions can increase task team effectiveness. Specifically, the second proposition of the team coaching model states that motivational coaching is most effective when given at the beginning, consultative coaching is most effective when given at the midpoint, and educational coaching is most effective when given at the end (Hackman \& Wageman, 2005). The third component of the team coaching model addresses the conditions under 
which coaching is and is not likely to improve performance. As discussed above, the impact of coaching interventions depends on the type of intervention as well as the timing of the intervention, but it also depends on the degree to which two other conditions are met. As stated in the team coaching model, the first condition is the degree to which key performance processes are externally constrained, and the second condition is the degree to which the group is a well-designed unit (Hackman \& Wageman, 2005). The proposition based on the first condition states that "coaching interventions are helpful only when they address team performance processes that are salient for a given task" ( $\mathrm{p}$. $280-281)$. Here, salient processes refer to those processes that are directly relevant for the team to successfully complete the task. If coaching interventions address processes that are not salient, they will be ineffectual at best. The proposition based on the second condition states "competent coaching interventions are more beneficial for groups that are well structured and supported than for those that are not" (Hackman \& Wageman, 2005, p. 282). A well-designed team is characterized by strong composition (e.g., high level of knowledge and skill) and strong contextual support (e.g., reward system).

Most of the research on coaching is found in the training literature, which specifically focuses on individual skill acquisition (Fournies, 1978). As a result, there has been relatively little published on the coaching of task-performing teams. One purpose of this study is to empirically test the second proposition, as stated by Hackman and Wageman (2005) in their team coaching model. The second proposition states that motivational coaching is most effective when given at the beginning, consultative 
coaching is most effective when given at the midpoint, and educational coaching is most effective when given at the end.

Hypothesis 1. Assuming the first and third components of the team coaching model are met (or controlled for), consultative team coaching will have a stronger positive effect on group performance when given at the midpoint rather than at the beginning (a priori).

\section{Collective Efficacy, Group Goals, and Group Cohesiveness}

As discussed earlier, the team coaching model posits there are three components of team coaching that affect team performance effectiveness. Besides team coaching, there are other factors that may influence group performance or vice versa such as collective efficacy, group goals, and group cohesiveness. Efficacy broadly refers to the beliefs held by either individuals or groups about their expected performance on a certain task (Bandura, 1982; Gist, 1987; Mulvey \& Klein, 1998). Until the early 1980s, individual self-efficacy had received a majority of the attention. Only recently, within the last few decades, has collective efficacy received more attention. Collective efficacy refers to "people's shared beliefs in their collective power to produce desired results." Simply put, collective efficacy is a group's perception of how they might/will perform on a particular group task (Bandura, 2000). Bandura (2000, p. 75) claims that "perceived collective efficacy fosters groups' motivational commitment to their missions, resilience to adversity, and performance accomplishments." Past research has demonstrated that collective efficacy is positively related to group goals, commitment, and performance, 
such that high efficacy groups set forth more difficult goals, are more committed to their goals, and generally perform better compared with low efficacy groups (Bandura, 1982; Prussia \& Kinicki, 1996).

Group goals are objectives that the group desires to reach. Goal-setting theory proposes that specific, difficult goals can lead to higher levels of task performance compared with easy or vague goals (e.g., "do your best”) (Locke \& Latham, 2006). The effects of goal-setting have primarily been studied with regard to individual performance and far fewer studies have explored these effects at the group level (Locke \& Latham, 1990). However, the studies that have investigated goal-setting at the group level have found a positive impact of group goals on performance. For example, Locke and Latham (1990) conducted a qualitative review of 41 studies where they concluded 93 percent of these studies showed a positive relationship between group goals and group performance. In their more recent analysis of 400 laboratory and field studies (Locke \& Latham, 2006), the relationship is still present. Therefore, individual and group goal-setting can result in better performance (Haslam et al., 2009, Mitchell \& Silver, 1990).

Group cohesiveness refers to the extent that group members feel like they belong to the group. Specifically, Carron et al. $(1998,2002)$ define cohesion as "a dynamic process that is reflected in the tendency of a group to stick together and remain united in the pursuit of its instrumental objectives and/or satisfaction of member affective needs" (p. 213). Based on this definition, it is generally assumed that greater cohesiveness leads to greater group performance. A meta-analysis, conducted by Mullen and Copper (1994), of 49 studies found that the relationship between cohesiveness and performance 
is positive, though small. Investigating the effects of goal commitment and cohesion in relation to group goals, Klein and Mulvey (1995) conducted a study where college students in naturally occurring groups met on the first day of class, were assigned a project, and had to agree upon a common goal for the group in finishing the project nearly five weeks later. Klein and Mulvey (1995) found that goals mediate the effects of cohesion on performance and therefore are the more immediate determinants of performance.

Hypothesis 2. Collective efficacy, group goals, and group cohesiveness will be highly correlated with each other.

Hypothesis 2A. Collective efficacy, group goals, and group cohesiveness will be positively related to group performance.

Feedback

Performance feedback also has the potential to affect group performance. Past research has uncovered mixed results on the effects of feedback interventions (FI) on group performance. Kluger and DeNisi (1996) discuss the discrepancies among FI research regarding its effects on overall group performance. In particular, they argue that past research has demonstrated the variability of FI effects on group performance, yet many FI researchers maintain that FIs consistently improve performance. Kluger \& DeNisi quote, "Feedback does not uniformly improve performance" (Balcazar, Hopkins, \& Suarez, 1985, p. 65). In their historical review and meta-analysis of FI effects on performance, Kluger \& DeNisi (1996) provide evidence that FIs generally improve 
performance $(\mathrm{d}=.41)$, but also found FIs that debilitate performance (in over $1 / 3$ of the cases) or show no apparent effects. Kluger \& DeNisi (1996) propose an FI theory to account for why FIs sometimes improve performance and in other cases diminish performance and conclude that FIs decrease in effectiveness as the locus of attention moves toward the self and simultaneously, away from the task. Perhaps, if the group is able to keep the locus of attention on the group and the task rather than on the self, it is possible to overcome the negative effects of failure feedback. In theory, team coaching should help guide the group members to think and act like a team by presenting the concept of group members' roles and suggesting alternative ways of approaching the task. In addition, there is some evidence that teams are more likely to use advice or suggestions after negative performance feedback. Choi and Levine (2004) allowed new members of a group to suggest new performance strategies after either positive or negative feedback. The new members were more influential when groups were told they had performed poorly as compared to situations where they were told they performed well. Thus, coaching may also be more influential after negative, as opposed to positive, team performance feedback.

Hypothesis 3. The effects of negative feedback on group performance may be moderated by team coaching. Groups who receive negative feedback and no coaching will perform worse than groups who receive negative feedback and coaching. 
Assuming group performance feedback allows members to establish expectations about their other group members and their subsequent interactions, how the feedback affects performance should depend whether it's positive or negative (Bettenhausen \& Murnighan, 1985; De Cremer \& Dijk, 2002). Snyder, Lassegard, and Ford (1986) investigated the effects of feedback in relation to image-maintenance processes"basking-in-reflected-glory" and "cutting-off-reflected-failure." They found that group members who received positive feedback, or were told their group had succeeded, tended to associate with their group more than members who received negative feedback, or were told their group had failed. Failure feedback tended to cause members to distance themselves from their group. Groups who received no feedback generally fell in between. Based on self-report and behavioral measures (taking and wearing of team badges), results indicated more support for group members distancing themselves from failure rather than group members associating themselves with success (Snyder et al., 1996).

Hypothesis 3A. Feedback will affect group cohesiveness such that negative feedback will reduce cohesiveness and positive feedback will increase cohesiveness.

After a group has received negative feedback, the phenomenon of "cutting-offreflected-failure" might also influence measures of collective efficacy such that group members would expect to be less successful the next time around. It's possible that in this case, negative feedback could lead to a decline in performance. De Cremer and Dijk (2002), referencing Fiske \& Taylor's (1984) work, address this concern saying that 
because group failure is often unexpected, it has a strong impact on the future actions and decisions of the group. Examining group identification levels in reference to feedback, De Cremer and Dijk (2002) suggest that failure feedback activates attributional processes that help explain why the failure happened, while success feedback is less likely to activate these same processes because success is consistent with people's optimistic expectations (Weiner, 1985). Therefore, these researchers believe when a group receives positive feedback, they can maintain the status quo and continue to succeed, but when they receive negative feedback, group identification could determine the effects of the feedback on their future contributions to the group (De Cremer \& Dijk, 2002). Feltz and Lirgg (1998) also discovered that teams who have already been successful in the past tend to develop strong efficacy beliefs that then lead to future successes. On the other hand, when teams experience a serious failure, their collective efficacy could decrease and then result in subsequent failures (Feltz \& Lirgg, 1998).

Hypothesis 3B. Positive feedback on group performance will have a neutral or positive effect on collective efficacy, whereas negative feedback on group performance will lead to a decrease in collective efficacy (Baker, 2001).

\section{Overview of Study}

The overall purpose of this study is to examine the effects of team coaching and feedback on group performance and see whether collective efficacy, group cohesiveness, and group goals also impact group performance. Participants in dyads received team 
performance tips either before the first task, between the two tasks, or not at all. All dyads also received either positive or negative feedback after the first task. For the task, dyads were instructed to diagnose emergency room patients from a list of medical diagnoses and symptoms. A challenging task was used in this study to encourage dyads to try different approaches. In addition, the task was set up such that the obvious way to approach the task would result in fewer correct diagnoses. This design was used to test the following hypotheses:

Hypothesis 1. Assuming the first and third components of the team coaching model are met (or controlled for), consultative team coaching will have a stronger positive effect on group performance when given at the midpoint rather than at the beginning (a priori).

Hypothesis 2. Collective efficacy, group goals, and group cohesiveness will be highly correlated with each other.

Hypothesis 2A. Collective efficacy, group goals, and group cohesiveness will be positively related to group performance.

Hypothesis 3. The effects of negative feedback on group performance may be moderated by team coaching. Groups who receive negative feedback and no coaching will perform worse than groups who receive negative feedback and coaching.

Hypothesis 3A. Feedback will affect group cohesiveness such that negative feedback will reduce cohesiveness and positive feedback will increase cohesiveness.

Hypothesis 3B. Positive feedback on group performance will have a neutral or positive effect on collective efficacy, whereas negative feedback on group performance will lead to a decrease in collective efficacy (Baker, 2001). 


\section{METHODS}

\section{Participants}

Two hundred forty-four students from a Midwestern university served as participants in one hundred twenty-two dyads. Three dyads were dropped because the procedure was not employed correctly by the experimenter, and seven other dyads were dropped because the groups diagnosed zero patients correctly on the first attempt and were told they did very well for their first time completing the task. After dropping these groups, there were 222 participants in 111 dyads. Participants were students from the introductory psychology participant pool. The ages of the participants ranged from 17 to 32 with an average age of 19 . Male participants made up 36.5\% of the sample, and $67.4 \%$ of the participants classified themselves as White, $12.2 \%$ as Asian, $9 \%$ as Latino, 3.6\% as African American, 2.3\% as Middle Eastern, and 5.4\% as Other. Participants received course credit for their participation.

\section{Procedure and Materials}

The participants were run in groups of two. Each participant signed a consent form before participating in the study. The research assistant first explained to the participants that this particular study examines factors that influence group performance, and in this study the participants would fill out questionnaires and perform a series of tasks to diagnose emergency room patients based on symptoms. As a motivator, the research assistant offered a prize incentive ( $\$ 25$ gift card to each group member) to the top five performing groups of the entire study. 
First, the research assistant gave detailed instructions about the task that the two participants would be asked to perform together. The task instructions should have given the participants an idea of how capable they might be at the task and how well they might perform. Each group was then given a few minutes to plan their strategy for approaching the task. Each participant filled out a multi-item scale (Time 1) that measured collective efficacy, group cohesiveness, and group goals (see next section for scale descriptions). When the participants notified the research assistant they were done with the pretest questionnaires, the research assistant handed out two packets to each participant. One packet consisted of the case descriptions of emergency room patients and the other packet had the medical diagnoses with corresponding symptoms. The packet of case descriptions had brief paragraphs about eight different patients. The eight patients were split into two sets - Set A and Set B — with both sets being equally difficult. The sets were created so that groups would be inclined to split up the task (suboptimal strategy) compared with diagnosing each patient together. Each group member possessed shared and unique information about each patient - this way, collaboration on each patient was necessary to produce the most accurate diagnosis.

The other packet contained a list of medical diagnoses with corresponding symptoms bulleted directly under each diagnosis, This information provided the groups with the necessary information to correctly diagnose the patients. Acting as a medical team, the participants were expected to correctly diagnose as many of the eight patients as possible in the allotted five minutes and were scored for accuracy. There was a timer on 
the table in front of the participants to increase pressure to perform, and the experimenter gave time updates as well.

There were two attempts of this task. After the first attempt, each group was given feedback about their performance. After filling out the same questionnaires from Time 1 (Time 2), they were given a chance to readdress their strategy for approaching the second attempt at the task. The second attempt consisted of diagnosing a different set of patients using the same difficulty level as the first attempt. After the second attempt, the participants filled out the last set of questionnaires (Time 3), similar to the first two sets, except with an additional measure of the helpfulness and comprehensiveness of the team performance tips, that is, if the team received team coaching at some point during the experiment.

Groups were randomly assigned to one of three coaching conditions - no coaching, a priori coaching, or coaching in the middle. Groups in the "no coaching" condition received no coaching. Groups in the "a priori coaching" condition received coaching before discussing their strategy, filling out Time 1 questionnaires, and the first attempt of the task. Groups that received coaching in the middle did so after they heard their feedback and filled out Time 2 questionnaires. The coaching consisted of team performance tips that could guide the team to think about ways of approaching the task differently to maximize group performance (See Appendix A). Ideally, the most efficient way to diagnose the patients should be to have both group members share their information about each patient and come to an agreement on a diagnosis for each. 
Groups were also randomly assigned to one of two feedback conditions - positive or negative. The groups were given accurate feedback on how they performed on the task, but it was worded in either a positive or negative light. In the positive feedback condition, the groups were told that they did well for their first time (e.g., "That was very good for your first time doing this."). In the negative feedback condition, the groups were told that they could improve significantly (e.g., "You still have a ways to go to be working optimally.").

\section{Measures/Variables}

Feedback Manipulation Check. The feedback manipulation check measured the group's perception of how well they felt they did on the first attempt of the task. It was measured by a single item, made on a scale from 1 (very poor) to 7 (extremely well) (e.g., “How would you rate your team's performance on the first round?”).

Coaching Manipulation Check. The coaching manipulation check measured how helpful, comprehensible, and clear the team performance tips were to each group member (e.g., "How helpful did you find the team performance tips?"). Scores were averaged for each member and then aggregated to form the group's perception of the team performance. Responses to all three items were made on a 7-point rating scale (e.g., $1=$ "not at all helpful" to 7 = "extremely helpful").

Collective efficacy (Time 1, Time 2, and Time 3). Collective efficacy is the extent to which a group or team expects to achieve its ultimate goal. In this study, "team" was emphasized as the unit of interest. For the purposes of this study, each group member filled out the collective efficacy measurement individually, and the scores of the group 
members were aggregated. A six-item scale to measure collective team efficacy was adapted from Bandura (1986) and Jung and Sosik (2002) (e.g., "My team can find solutions to problems with its performance" and "My team had the skills necessary to do well at this task" (See Appendix B). Responses to all items were made on a 7-point rating scale $(1=$ strongly disagree, $2=$ disagree, $3=$ disagree somewhat, $4=$ neutral, $5=$ agree somewhat, $6=$ agree, $7=$ strongly agree).

Group goals. Each individual estimated, or made a goal, of how many patients he/ she thought the group could diagnose in the allotted amount of time. For the group goal, the two group members' estimates were averaged.

Feedback. The performance feedback was manipulated. Groups were randomly assigned to a positive or negative feedback condition. The groups were given accurate feedback on how they performed on the task, but it was worded in either a positive or negative light. In the positive feedback condition, the groups were told that they did well for their first time (e.g., "That was very good for your first time doing this."). In the negative feedback condition, the groups were told that they could significantly improve (e.g., "You still have a ways to go to be working optimally.").

Performance Outcome. Performance outcome was recorded as the number of patients successfully diagnosed, with a highest possible score of 8 . There was a performance outcome measure for the first attempt and another for the second attempt. In addition, the attempted proportion correct was recorded as the ratio of patients successfully diagnosed out of the number of patients the group attempted to diagnose (e.g., wrote down a diagnosis and did not leave it blank). 
Group Cohesiveness. Group cohesiveness refers to the extent that group members feel like they belong to the group. It acts as a sort of force that brings group members together. All four items were rated using a 7-point scale rating scale described above. See Appendix B.

Strategy used for task. Groups were video recorded, and these recordings were used to determine what strategies groups used for approaching the task in both attempts See Appendix C.

\section{RESULTS}

\section{Aggregation of Data}

Team members' collective efficacy and cohesion scores were aggregated to provide team collective efficacy and cohesion scores. In addition, group goal estimates for each task were averaged across group members for a single team group goal for each attempt of the task. The responses to the feedback and coaching manipulation checks were also aggregated.

\section{Manipulation Checks}

I conducted a 3 (Coaching condition: No coaching, A priori coaching, Coaching in the middle) x 2 (Feedback: Positive, Negative) ANOVA on the feedback manipulation check ("How would you rate your team's performance on the first round?"). The analysis revealed a significant main effect of feedback predicting how well the group rated their performance, $\underline{\mathrm{F}}(1,105)=27.49, \underline{\mathrm{p}}<.001$. As expected, this suggests that groups who received negative feedback $(\underline{\mathrm{M}}=3.41)$ rated their performance significantly worse than groups who received positive feedback $(\underline{\mathrm{M}}=4.63)$. There was not a significant effect 
of coaching, nor a significant Coaching $\mathrm{x}$ Feedback interaction predicting the feedback manipulation check- $\underline{\mathrm{F}}(2,105)=.80, \underline{\mathrm{p}}=.454$ and $\underline{\mathrm{F}}(2,105)=1.14, \underline{\mathrm{p}}=.325$ respectively.

I conducted a 3 (Coaching condition: No coaching, A priori coaching, Coaching in the middle) x 2 (Feedback: Positive, Negative) ANOVA on the coaching manipulation check (three-item scale assessing perceived helpfulness, comprehensibility, and clarity of team performance tips) for groups who received coaching (a priori or in the middle). This analysis revealed that there was not a significant effect of coaching predicting the perceived helpfulness, comprehensibility, and clarity of the team performance tips, $\underline{\mathrm{F}}(1$, $73)=.58, \underline{p}=.450$. Contrary to expectations, this suggests that the groups who received coaching in the middle $(\mathrm{M}=4.89)$ did not rate the team performance tips as significantly better than groups who received a priori coaching $(\mathrm{M}=4.71)$. Overall, however, these means indicate that groups who received coaching found the team performance tips to be relatively helpful, comprehensible, and clear. By making the team performance tips more straightforward, there might be differences between groups in future research. In addition, there was not a significant effect of feedback, nor a significant Coaching x Feedback interaction predicting the coaching manipulation check- $\underline{F}(1,73)=.50, \underline{p}=.483$ and $\underline{F}$ $(1,73)=.004, \underline{p}=.951$-respectively.

\section{Dependent Variables}

Performance. I conducted a 3 (Coaching condition: No coaching, A priori coaching, Coaching in the middle; between) x 2 (Feedback: Positive, Negative; between) x 2 (Group performance: Task 1, Task 2; within) ANOVA on the number of correct 
diagnoses made by dyads. The analysis revealed a significant main effect of time predicting group performance, $\underline{\mathrm{F}}(1,105)=52.42, \underline{\mathrm{p}}<.001$. This suggests that groups, on average, collapsing across coaching conditions and feedback interventions, improved between Task $1(\underline{M}=2.43)$ and Task $2(\underline{M}=3.63)$. The Time x Feedback interaction predicting group performance was not significant, $\underline{\mathrm{F}}(1,105)=.21, \underline{\mathrm{p}}=.645$. The Time $\mathrm{x}$ Coaching interaction predicting group performance was significant, $\underline{\mathrm{F}}(2,105)=3.30, \underline{p}$ $=.041$ (See Figure 1). However, the overall Coaching x Feedback x Time interaction was not significant (Task 1 and Task 2$), \underline{F}(2,105)=1.51, \underline{p}=.225$.

Figure 1: Means of group performance across coaching conditions and time

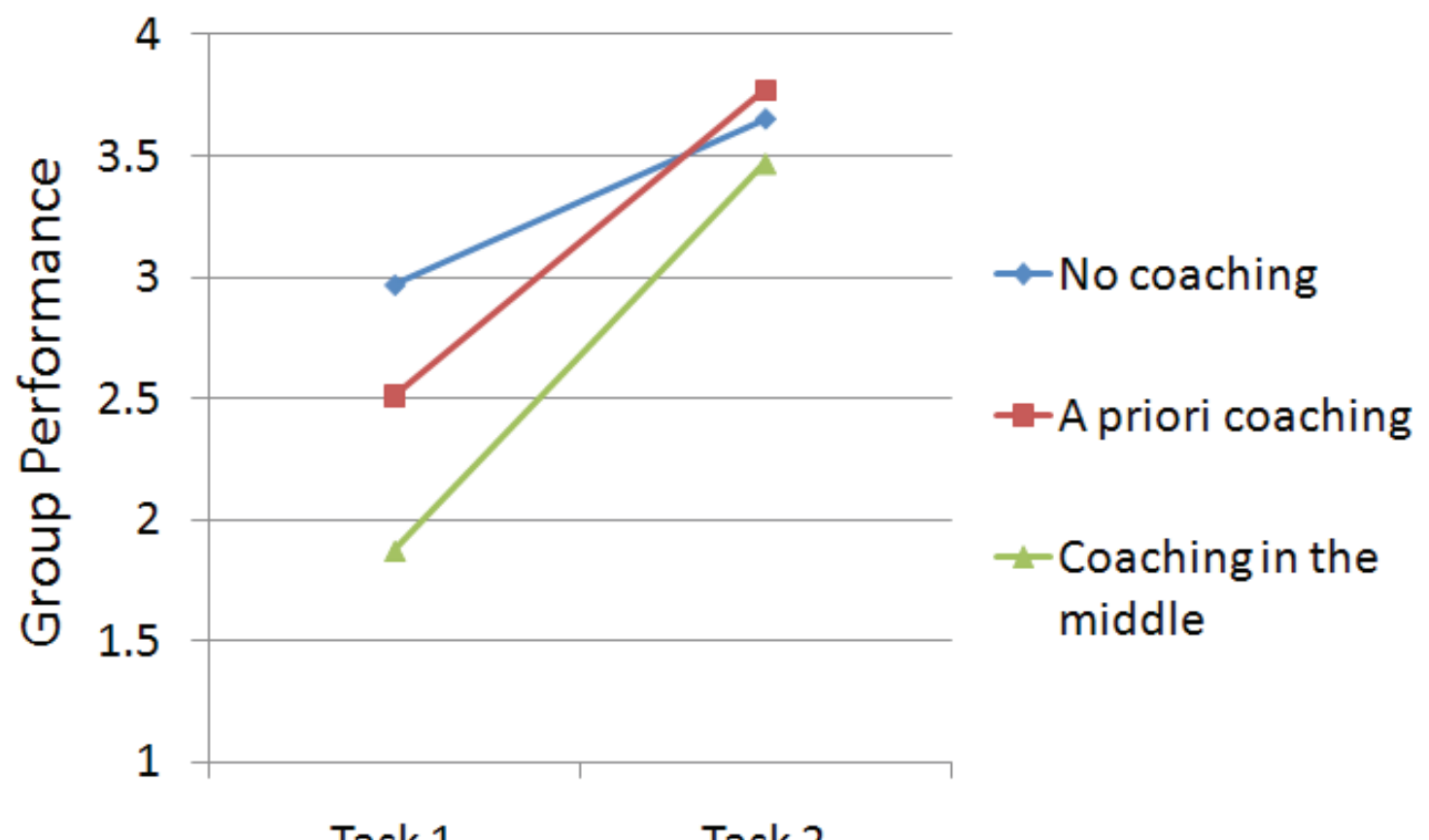

Task $1 \quad$ Task 2

I conducted simple effects tests to explore the significant Time $\mathrm{x}$ Coaching interaction predicting group performance. The first analysis revealed that for groups in the "no coaching" condition, group performance on the first attempt of the task (M 
$=2.97$ ) was significantly lower than group performance on the second attempt of the task $(\mathrm{M}=3.65), \underline{\mathrm{F}}(1,33)=4.45, \underline{\mathrm{p}}=.043$. Because these groups received no coaching, the improvement in group performance could be due to practice effects, among other things. For groups in the "no coaching" condition, the average group performance on the second attempt of the task was .362 standard deviations higher than the average group performance in the first attempt of the task $(d=.362)$. The second analysis revealed that for groups in the "a priori coaching" condition, group performance on the first attempt of the task $(M=2.51)$ was significantly lower than group performance on the second attempt of the task $(\mathrm{M}=3.77), \underline{\mathrm{F}}(1,38)=31.01, \underline{\mathrm{p}}<.001$. For groups in the "a priori coaching" condition, the average group performance on the second attempt of the task was .891 standard deviations higher than the average group performance in the first attempt of the task $(d=.891)$. The third analysis revealed that for groups that received coaching in the middle of the two tasks, group performance on the first attempt of the task $(M=1.87)$ was significantly lower than group performance on the second attempt of the task $(\mathrm{M}=3.47), \underline{\mathrm{F}}(1,37)=32.62, \underline{\mathrm{p}}<.001$. For groups that received coaching in the middle, the average group performance on the second attempt of the task was .928 standard deviations higher than the average group performance in the first attempt of the task $(\mathrm{d}=.928)$. Thus, the effects of coaching appear largest in the "coaching in the middle" condition. However, this is largely due to their early poor performance, not to superior performance relative to the other two conditions at time 2 . Therefore, these results do not support Hypothesis 1. 
Table 1: Means of group performance on Task 1 and Task 2 across coaching conditions

\begin{tabular}{|l|c|c|c|c|}
\hline & No Coaching & A priori Coaching & Coaching in the middle & \\
\hline \multirow{2}{*}{ Task 1 } & $\frac{\mathrm{M}}{\mathrm{N}}=2.97$ & $\underline{\mathrm{M}}=2.51$ & $\underline{\mathrm{M}}=1.87$ & 2.45 \\
\hline \multirow{2}{*}{ Task 2 } & $\underline{\mathrm{M}}=3.65$ & $\underline{\mathrm{N}}=39$ & $\underline{\mathrm{N}}=38$ & $\underline{\mathrm{M}}=3.47$ \\
\hline & $\underline{\mathrm{N}}=34$ & $\underline{\mathrm{N}}=39$ & $\underline{\mathrm{N}}=38$ & 3.63 \\
\hline & 3.31 & 3.14 & 2.67 & \\
\hline
\end{tabular}

Collective efficacy. To determine whether time of measurement (Time 1, 2, or 3), coaching condition, and feedback impacted collective efficacy, I conducted a 3 (Time of measurement: Time 1, Time 2, Time 3; within) x 3 (Coaching condition: No coaching, A priori coaching, Coaching in the middle; between) x 2 (Feedback: Positive, Negative; between) ANOVA. The analysis revealed a significant main effect of time of measurement predicting collective efficacy, $\underline{\mathrm{F}}(2,210)=17.79, \underline{\mathrm{p}}<.001$. This suggests that groups, on average, collapsing across coaching conditions and feedback interventions, decreased in collective efficacy over time-Time $1(\underline{M}=5.91)$, Time 2 $(\underline{\mathrm{M}}=5.65)$, and Time $3(\underline{\mathrm{M}}=5.49)$. The group's expectations to succeed most likely decreased over time because the group members had experienced the difficulty of the task and thought they would be less likely to succeed on the second attempt. The Time $x$ Feedback interaction predicting collective efficacy was not significant, $\underline{F}(2,210)=$ $1.77, \underline{p}=.173$. This finding does not support the prediction that positive feedback on group performance would have a neutral or positive effect on collective efficacy, whereas negative feedback on group performance would lead to a decrease in collective efficacy (Hypothesis 3B). The Time x Coaching interaction predicting collective efficacy was also nonsignificant, $\underline{\mathrm{F}}(4,210)=1.33, \underline{\mathrm{p}}=.261$. Finally, the overall Time $\mathrm{x}$ Coaching 
$x$ Feedback interaction was not significant, $\underline{F}(4,210)=.82, \underline{p}=.511$. Based on these results, I can also conclude that the effects of negative feedback on group performance were not moderated by team coaching (Hypothesis 3).

Group Cohesiveness. To determine whether time of measurement (Time 1, 2, or 3), coaching condition, and feedback impacted group cohesiveness, I conducted a 3 (Time of measurement: Time 1, Time 2, Time 3; within) x 3 (Coaching condition: No coaching, A priori coaching, Coaching in the middle; between) x 2 (Feedback: Positive, Negative; between) ANOVA. The analysis revealed a significant main effect of time of measurement predicting group cohesiveness, $\underline{\mathrm{F}}(2,210)=35.41, \underline{\mathrm{p}}<.001$. This suggests that groups, on average, collapsing across coaching conditions and feedback interventions, increased in group cohesiveness over time-Time $1(\underline{M}=5.63)$, Time $2(\underline{M}$ $=5.89)$, and Time $3(\underline{\mathrm{M}}=6.00)$. Though the task was difficult, the more time the group members spent working together, the more cohesive they felt as a team. The Time $\mathrm{x}$ Feedback interaction predicting group cohesiveness was not significant, $\underline{F}(2,210)=.64$, $\mathrm{p}=.531$. The Time $\mathrm{x}$ Coaching interaction predicting group cohesiveness was significant, $\underline{F}(4,210)=2.44, \underline{p}=.048$. However, the overall Time $x$ Coaching $x$ Feedback interaction was not significant, $\underline{F}(4,210)=1.55, \underline{p}=.190$. From these results, Hypothesis 3 A was not confirmed. Feedback did not appear to affect group cohesiveness. In other words, negative feedback did not reduce cohesiveness and positive feedback did not increase cohesiveness.

I conducted simple effects tests to explore the significant Time $\mathrm{x}$ Coaching interaction predicting group cohesiveness. The simple effects analyses showed significant 
increases over time for all three coaching conditions $-\underline{F}(2,66)=3.87, \underline{p}=.026, \eta^{2}$ $=.105$ (no coaching), $\underline{\mathrm{F}}(2,76)=14.99, \underline{\mathrm{p}}<.001, \eta^{2}=.283$ (a priori coaching), and $\underline{F}(2,74)=23.77, \underline{p}<.001, \eta^{2}=.391$ (coaching in the middle). See Figure 2. These results indicate that the size of the increase in group cohesiveness for the "coaching in the middle" groups was strongest. However, the effect seems to be driven by low cohesiveness scores at time one relative to the other two groups_-"a priori coaching" and "no coaching." Groups in the "a priori coaching" condition scored highest on cohesiveness throughout the experiment which suggests that a priori team coaching may lead to higher levels of group cohesiveness.

Figure 2: Group cohesiveness over time, across coaching conditions

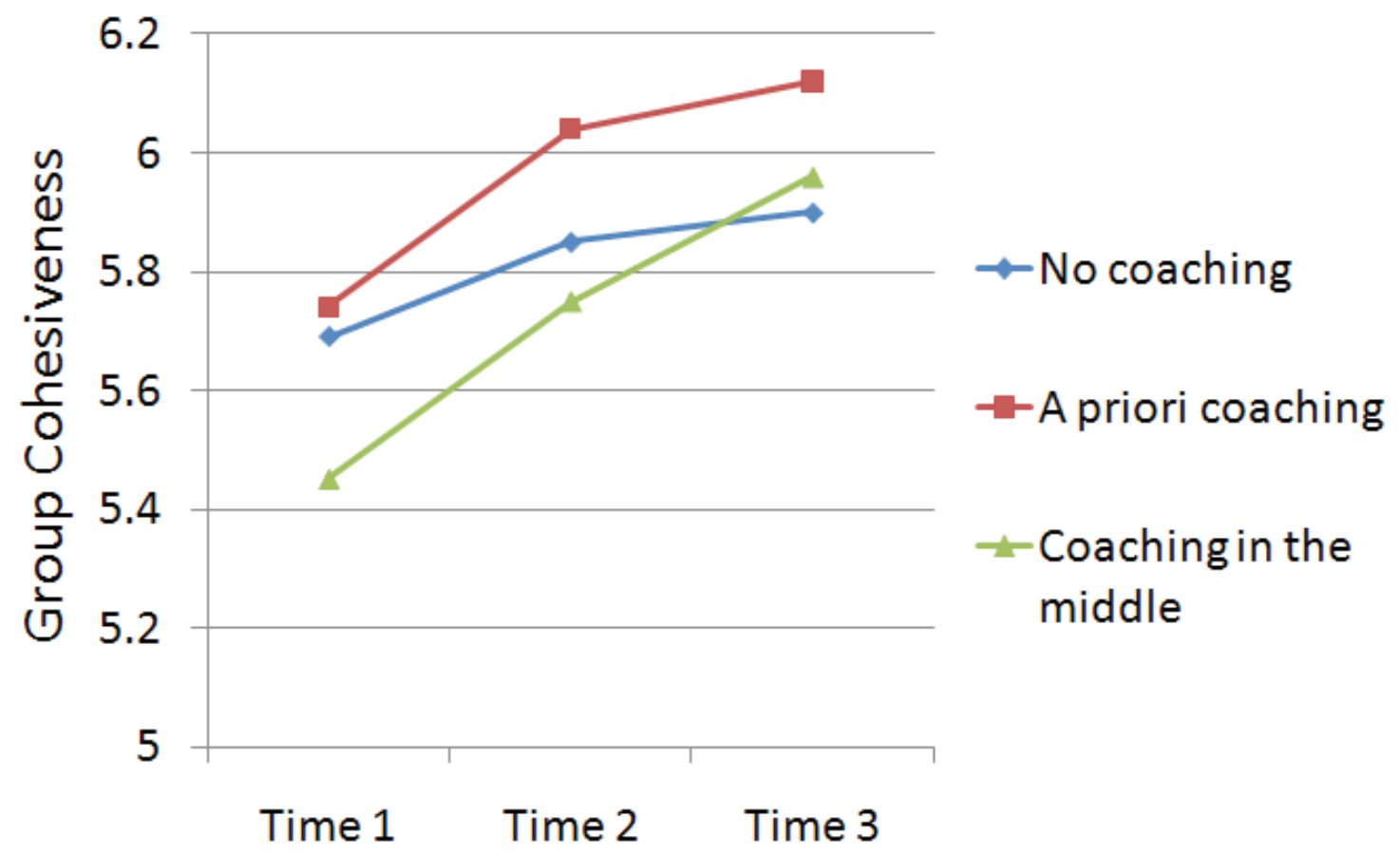


Group Goals. A 2 (Time of measurement: Time 1, Time 2; within) x 3 (Coaching condition: No coaching, A priori coaching, Coaching in the middle; between) x 2 (Feedback: Positive, Negative; between) ANOVA was conducted on the average goals set by the dyad members. The analysis revealed a significant main effect of time of measurement predicting group goals, $\underline{\mathrm{F}}(1,105)=70.95, \underline{\mathrm{p}}<.001$. On average, collapsing across coaching conditions and feedback interventions, group goals decreased over time-Time $1(\underline{M}=6.79)$ and Time $2(\underline{M}=5.77)$. Similar to the results examining collective efficacy, group goals most likely decreased over time because the groups made more realistic goals after experiencing the difficult task for the first time. The Time $\mathrm{x}$ Feedback interaction predicting group goals was not significant, $\underline{F}(1,105)=.84, \underline{p}=$ .362. The Time $x$ Coaching interaction predicting group goals was significant, $\underline{F}(2,105)$ $=3.96, \underline{p}=.022$. However, the overall Time $\times$ Coaching $\times$ Feedback interaction was not significant, $\underline{\mathrm{F}}(2,105)=1.18, \underline{\mathrm{p}}=.310$.

I conducted simple effects tests to explore the significant Time $\mathrm{x}$ Coaching interaction predicting group goals. Group goals decreased from Time 1 to Time 2 for all three groups $-\underline{F}(1,33)=8.89, \underline{p}=.005, d=.510$ (no coaching), $\underline{F}(1,38)=24.10, \underline{p}<$ $.001, \mathrm{~d}=.782$ (a priori coaching), and $\underline{\mathrm{F}}(1,37)=64.93, \underline{\mathrm{p}}<.001, \mathrm{~d}=1.304$ (coaching in the middle). See Figure 3. All groups started with comparable goals at Time 1. The "no coaching" and "a priori coaching" conditions show a similar decrease in goals over time with the "no coaching" condition posting slightly higher goals compared with the "a priori" condition. Contrary to expectations, the "coaching in the middle" condition shows the sharpest decrease in goals over time. 
Figure 3: Group goals over time, across coaching conditions

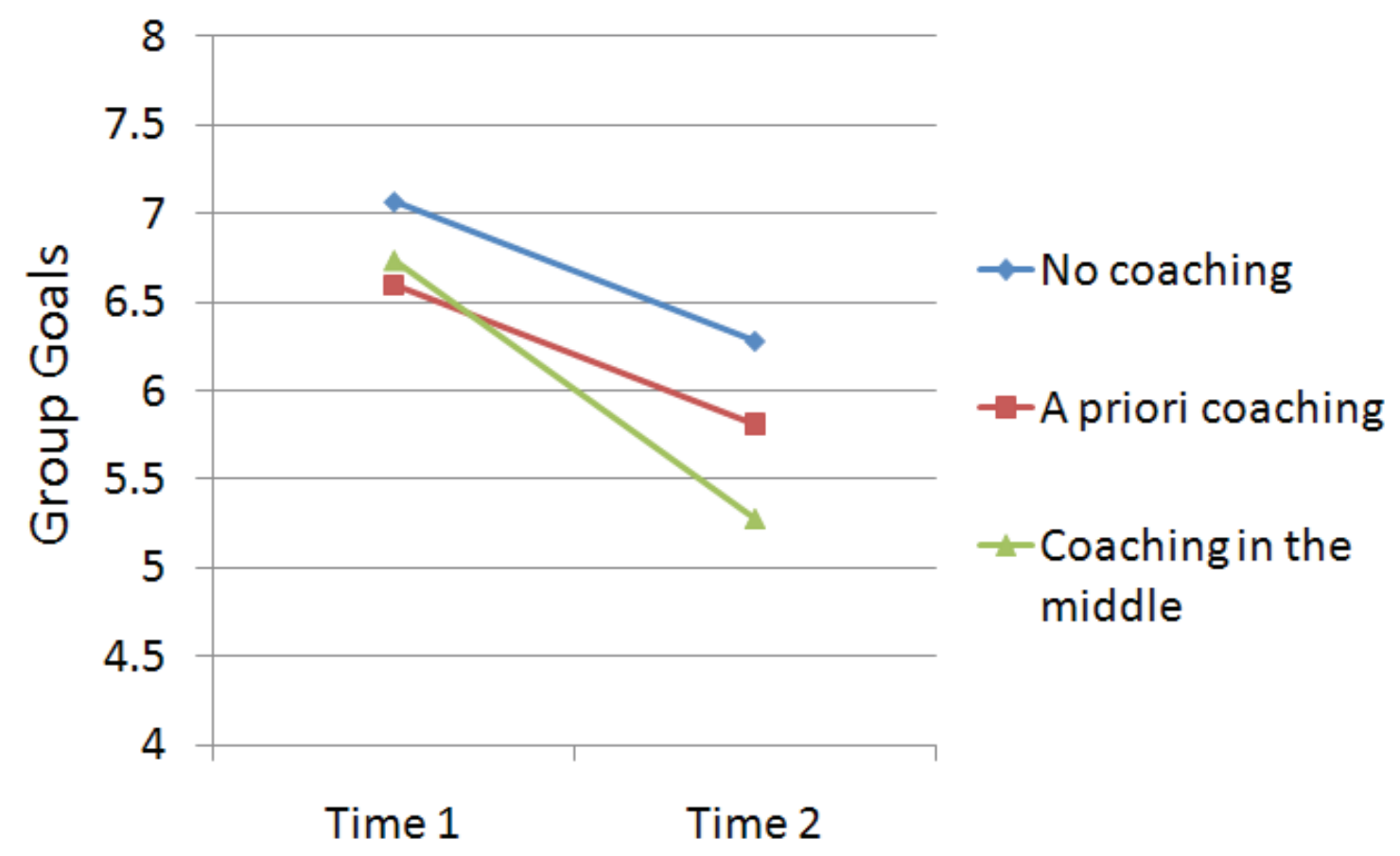

Strategies. The optimal strategy for approaching the task consisted of both group members collaborating on each patient. Because group members had shared and unique information about each patient, sharing the symptoms from both group members' case descriptions should allow for greater accuracy in diagnosing the patients. Video recordings of groups performing the task were coded for strategies (See Appendix C). There were five general strategies that emerged during the group task-(1) split the task up by sets (e.g., one group member diagnoses Set A and the other group member diagnoses Set B), (2) group members work together on each patient but do not share all of the symptoms, (3) group members work together and share all of the symptoms, (4) one group member reads the case description while the other flips through the diagnoses 
packet, and (5) other (e.g., spending time underlining all the symptoms and then flipping through the diagnoses packets, calling out a diagnosis when they found one).

Table 2: Percentage of groups who utilized each strategy for Task 1 and Task 2

\begin{tabular}{|l|c|c|}
\hline \multicolumn{1}{|c|}{ Strategy } & Task 1 & Task 2 \\
\hline 1. Split task up by sets & 44.7 & 37.6 \\
\hline 2. Work together but share few symptoms & 13.6 & 16.8 \\
\hline 3. Work together and share all symptoms & 22.3 & 34.7 \\
\hline 4. One person reads while other checks diagnoses packet & 9.7 & 5.0 \\
\hline 5. Other & 9.7 & 5.9 \\
\hline \multicolumn{1}{|c|}{ Total } & 100 & 100 \\
\hline
\end{tabular}

Sharing symptoms was predicted to be the optimal way to approach the task since each group member had only a portion of the information to diagnose the patients. For the purposes of the analyses, strategy 3 was considered the optimal strategy in approaching the task, and strategy 2 was considered the second best strategy. Strategy improvement (e.g., change from strategy 4 to strategy 3 or 2) or maintenance (e.g., start with strategy 3 and stick with it) was recorded for Task 1 and Task 2 for each group. If a group started out with a suboptimal strategy and changed to a better strategy or if a group started out with the optimal strategy and stayed with it, I counted that as strategy improvement/maintenance. However, if a group first approached the task via strategy 1 and did not change their strategy, it was not counted as strategy improvement. Strategy improvement/maintenance was coded as present (yes) or not present (no) for three different time points_-within Task 1, between Task 1 and 2, and within Task 2.

A 3 (coaching) x 2 (feedback) ANOVA predicting strategy improvement was conducted for all three time points. The analysis revealed that there was not a significant 
effect of feedback predicting strategy improvement within Task 1, between Task 1 and 2 , and within Task $2-\underline{F}(1,94)=.62, \underline{p}=.435, \underline{F}(1,94)=.01, \underline{p}=.918$, and $\underline{F}(1,94)$ $=.11, \underline{p}=.738$ - respectively. However, there was a significant main effect of coaching predicting strategy improvement between Tasks 1 and $2-\underline{F}(2,94)=3.99, \underline{p}=.022, \eta^{2}=$ .078 - but no significant effects for within Task 1 or within Task $2-\underline{F}(2,94)=.49, \underline{p}=$ $613, \eta^{2}=.010$ and $\underline{F}(2,94)=1.50, \underline{p}=.228, \eta^{2}=.031$-respectively. See Table 3. This suggests that coaching led to changes in strategies between the two tasks. Specifically, coaching led to shifts toward sharing symptoms. There was not a significant Coaching $\mathrm{x}$ Feedback interaction predicting strategy improvement for any of the three time points- $\underline{F}$ $(2,94)=.15, \underline{p}=.862, \underline{F}(2,94)=.86, \underline{p}=.425$, and $\underline{F}(2,94)=.39, \underline{p}=.677$.

Table 3: Percentage of groups (out of all groups) that showed strategy improvement/ maintenance within Task 1, between Tasks 1 and 2, and within Task 2, as a function of coaching

\begin{tabular}{|l|c|c|c|}
\hline & Within Task 1 & Between Tasks 1 and 2 & Within Task 2 \\
\hline No coaching & 10 & 16 & 12 \\
\hline A priori coaching & 12 & 10 & 12 \\
\hline Coaching in the middle & 14 & 23 & 19 \\
\hline
\end{tabular}

I conducted a 3 (coaching) x 2 (feedback) x 2 (strategy improvement: yes, no) ANOVA for all three time points on the number of correct diagnoses made by dyads. Within the first task, all interactions-Time $\mathrm{x}$ Feedback, Time $\mathrm{x}$ Coaching, Time $\mathrm{x}$ Strategy Improvement, Time x Feedback x Coaching, Time x Feedback x Strategy Improvement, Time x Coaching x Strategy Improvement and Time x Feedback x Coaching x Strategy Improvement-were nonsignificant. Between the two tasks, the interactions were again nonsignificant. Within the second task, there were no significant 
interactions. However, the Time x Coaching x Strategy Improvement interaction showed a trend toward significance, $\underline{\mathrm{F}}(2,88)=2.07, \underline{\mathrm{p}}=.132$.

Contrary to expectations, strategy improvement did not lead to more correct diagnoses. With this in mind, I further investigated team performance. Since the two predominant strategies were either to split it up by sets or to work together and share symptoms (few or all), performance was compared between these two groups. I conducted a 3 (coaching) x 2 (feedback) x 2 (strategy: split it up by sets, work together and share symptoms) ANOVA predicting group performance on Task 1 and another predicting group performance on Task 2. Results indicated that for performance on Task 1, there were significant main effects of feedback and coaching $-\underline{F}(1,64)=6.14$, $\underline{p}=.016, \eta^{2}=.088$ and $\underline{\mathrm{F}}(2,64)=7.31, \underline{\mathrm{p}}=.001, \eta^{2}=.186$ - as well as a marginally significant effect of strategy, $\underline{\mathrm{F}}(1,64)=3.89, \underline{\mathrm{p}}=.053, \eta^{2}=.057$. Groups who received negative feedback $(\underline{M}=2.15)$ performed significantly worse than groups who received positive feedback $(\underline{\mathrm{M}}=3.14)$. In addition, groups who received no coaching $(\underline{\mathrm{M}}=$ 3.04), a priori coaching $(\mathrm{M}=3.05)$, and coaching in the middle $(\underline{\mathrm{M}}=1.93)$ performed significantly different from each other. Specifically, groups who received no coaching and a priori coaching performed significantly better than groups who received coaching in the middle. Finally, the difference between groups who split the task up by sets $(\underline{M}=2.93)$ and those that worked together $(\underline{\mathrm{M}}=2.24)$ was marginally significant. In addition, there was a significant Coaching $x$ Feedback $x$ Strategy interaction, $\underline{F}(2,64)=3.20, \underline{p}=.047$, $\eta^{2}=.091$ (See Tables 4 and 5). As seen in Table 4, the group performance for groups who received no coaching did not differ between strategies, nor did it for the "coaching in the 
middle" condition. The "coaching in the middle" groups had not yet received coaching at this point. However, groups who received a priori coaching show the largest decline between strategies, with working together being the suboptimal strategy. This may indicate that the groups who attempted a new strategy in light of their coaching were not yet familiar enough with working together to employ the strategy successfully. In other words, they may have overdone the symptom sharing (e.g., read every single word in the case description instead of sharing just the symptoms) which would slow them down substantially.

Table 4: Means of group performance on Task 1 for groups who received negative feedback across coaching conditions and strategies

\begin{tabular}{|c|c|c|c|c|}
\hline & No coaching & $\begin{array}{c}\text { A priori } \\
\text { coaching }\end{array}$ & $\begin{array}{c}\text { Coaching in the } \\
\text { middle }\end{array}$ & Total \\
\hline Split by sets & 2.45 & 3.50 & 1.40 & 2.45 \\
\hline Work together & 2.75 & 2.33 & 1.22 & 2.10 \\
\hline Total & 2.60 & 2.92 & 1.31 & \\
\hline
\end{tabular}

As seen in Table 5, groups who received a priori coaching performed about the same between strategies, as did groups who received coaching in the middle. However, groups who received no coaching performed worse when working together compared with splitting it up by sets. This could be because they had not received proper coaching on how to approach the task. 
Table 5: Means of group performance on Task 1 for groups who received positive feedback across coaching conditions and strategies

\begin{tabular}{|c|c|c|c|c|}
\hline & No coaching & $\begin{array}{c}\text { A priori } \\
\text { coaching }\end{array}$ & $\begin{array}{c}\text { Coaching in the } \\
\text { middle }\end{array}$ & Total \\
\hline Split by sets & 4.11 & 3.29 & 2.57 & 3.32 \\
\hline Work together & 2.00 & 3.20 & 2.57 & 2.59 \\
\hline Total & 3.06 & 3.25 & 2.57 & \\
\hline
\end{tabular}

For Task 2, there were two marginally significant effects for feedback and strategy- $\underline{F}(1,75)=3.83, \underline{p}=.054, \eta^{2}=.049$ and $\underline{F}(1,75)=3.27, \underline{p}=.075, \eta^{2}=.042$.

The performance difference between groups who received negative feedback $(\mathrm{M}=3.19)$ and those who received positive feedback $(M=3.91)$ was marginally significant. In addition, there was a marginally significant performance difference between groups who split it up by sets $(M=3.97)$ and those who worked together $(M=3.27)$. Perhaps the performance difference between the two groups — split it up by sets and work togetherarises because in the latter, some groups shared all the symptoms while some only shared a few.

To examine the differences between groups who shared only a few of the symptoms and those who shared all of the symptoms, I conducted a 3 (coaching) x 2 (feedback) x 2 (symptom sharing: few or all) ANOVA predicting performance on Task 1 and another predicting performance on Task 2. For Task 1, there was a significant main effect of coaching predicting group performance, $\underline{\mathrm{F}}(2,20)=4.56, \underline{p}=.023, \eta^{2}=.313$. Groups who received no coaching $(M=2.60)$, a priori coaching $(M=2.82)$, and coaching in the middle $(\mathrm{M}=1.73)$ performed significantly different from each other. In addition, 
there was a marginally significant Coaching x Feedback x Symptom Sharing interaction predicting group performance, $\underline{\mathrm{F}}(1,20)=3.27, \underline{\mathrm{p}}=.086, \eta^{2}=.140$.

For Task 2, there was a significant main effect of feedback, $\underline{F}(1,30)=9.07, \underline{p}=$ $.005, \eta^{2}=.232$, and a marginally significant effect of symptom sharing, $\underline{F}(1,30)=2.94$, $\mathrm{p}=.097, \eta^{2}=.089$. The significant main effect of feedback suggests that groups who received negative feedback $(\underline{\mathrm{M}}=3.00)$ performed significantly worse than groups who received positive feedback $(\underline{\mathrm{M}}=3.85)$. Also, there was a marginally significant difference between groups who shared few symptoms $(\underline{M}=2.75)$ and those who shared all the symptoms $(\underline{\mathrm{M}}=3.50)$. There were also significant Feedback x Coaching and Coaching $\mathrm{x}$ Symptom Sharing interactions predicting group performance on Task $2-\underline{F}(2,30)=$ $6.47, \underline{p}=.005, \eta^{2}=.301($ See Table 6$)$ and $\underline{F}(2,30)=6.95, \underline{p}=.003, \eta^{2}=.317($ See Table 7)_-as well as a marginally significant Feedback x Symptom Sharing interaction, $\underline{F}$ (1, 30) $=3.93, \underline{p}=.005, \eta^{2}=.057$

Table 6: Means of group performance on Task 2 across coaching and feedback conditions

\begin{tabular}{|c|c|c|c|c|}
\hline & No coaching & $\begin{array}{c}\text { A priori } \\
\text { coaching }\end{array}$ & $\begin{array}{c}\text { Coaching in the } \\
\text { middle }\end{array}$ & Total \\
\hline $\begin{array}{c}\text { Negative } \\
\text { feedback }\end{array}$ & 3.27 & 2.60 & 2.91 & 2.93 \\
\hline $\begin{array}{c}\text { Positive } \\
\text { feedback }\end{array}$ & 3.20 & 4.14 & 5.00 & 4.11 \\
\hline Total & 3.24 & 3.37 & 3.96 & \\
\hline
\end{tabular}


Table 7: Means of group performance on Task 2 across coaching conditions and symptom sharing strategies

\begin{tabular}{|c|c|c|c|c|}
\hline & No coaching & $\begin{array}{c}\text { A priori } \\
\text { coaching }\end{array}$ & $\begin{array}{c}\text { Coaching in the } \\
\text { middle }\end{array}$ & Total \\
\hline Share few & 2.50 & 2.00 & 3.50 & 2.67 \\
\hline Share all & 3.70 & 3.80 & 2.88 & 3.46 \\
\hline Total & 3.10 & 2.90 & 3.19 & \\
\hline
\end{tabular}

Opposite from predicted, groups who received coaching in the middle did not perform better on Task 2 when they shared all the symptoms as opposed to a few of the symptoms. However, groups who received no coaching or a priori coaching did do better when they shared all the symptoms instead of just a few of the symptoms. These results could indicate that groups who received coaching in the middle were spending too much time sharing (e.g., reading their entire case descriptions out loud). Sharing symptoms was emphasized in the team performance tips, as well as speed. However, the strategy of sharing symptoms may have slowed the groups down.

\section{Correlational Analyses}

Collective efficacy, group goals, and group cohesiveness. It was predicted that collective efficacy, group goals, and group cohesiveness would be highly correlated with each other. Seen in Table 8, collective efficacy at Time 1 and Time 2 is positively correlated with group goal 1 and group goal 2. Collective efficacy at Time 3 is positively correlated with group goal 1 but not with group goal $2, \mathrm{r}=.27$ and $\mathrm{r}=.12$, respectively. Also seen in Table 8, collective efficacy at Time 1, 2, and 3 is positively correlated with group cohesiveness at Time 1, 2, and 3. 
In addition, it was predicted that collective efficacy, group goals, and group cohesiveness would be positively correlated to group performance. As shown in Table 8 , collective efficacy at Time 2 was positively correlated with group performance on the first attempt, $r=.29$. Collective efficacy at Time 3 was positively correlated with group performance on the second attempt, $r=.63$. In addition, cohesiveness at Time 3 , group goal 1, and group goal 2 were positively correlated with group performance on the second attempt of the task, $\mathrm{r}=.19, \mathrm{r}=.21$ and $\mathrm{r}=.20$, respectively. 


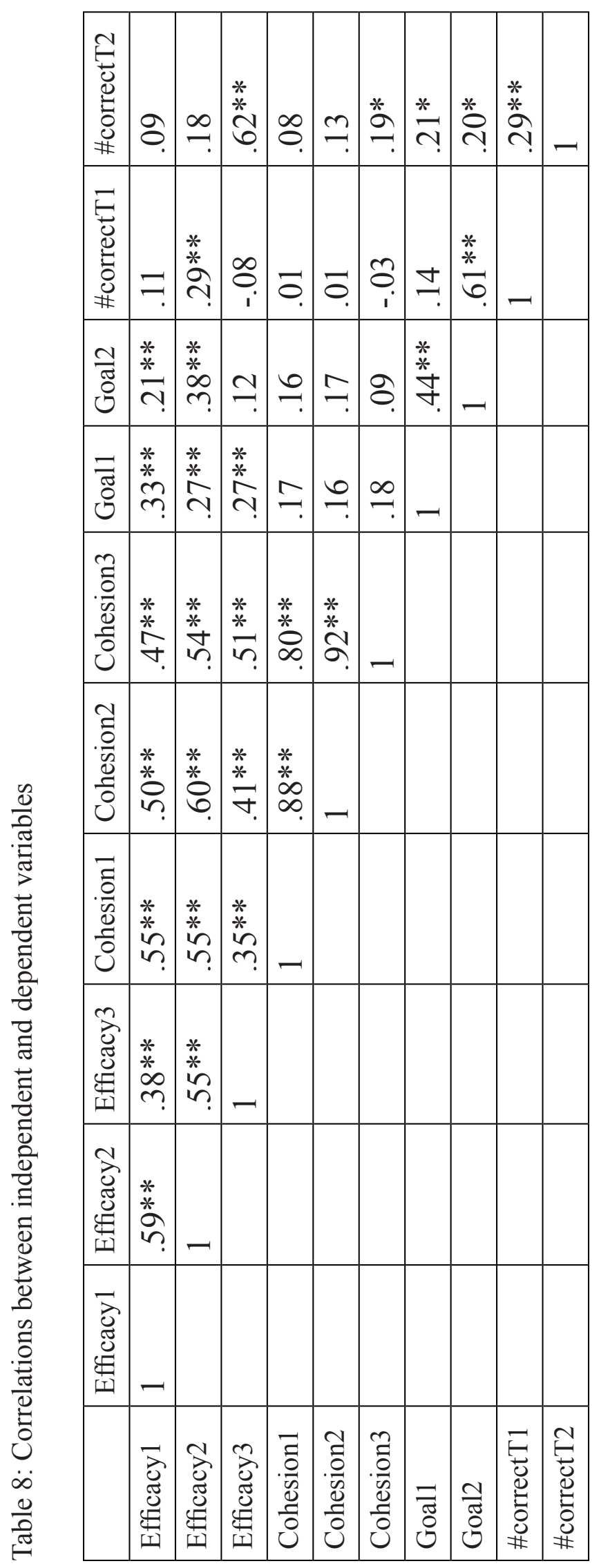




\section{DISCUSSION}

The purpose of this study was to examine the effects of team coaching and feedback on group performance and see whether collective efficacy, group cohesiveness, and group goals also impact group performance. Participants in dyads received team performance tips either before the first task, between the two tasks, or not at all. Dyads also received either positive or negative feedback after the first task. A challenging task was used in this study to encourage dyads to try different approaches. In addition, it would have been difficult to use negative feedback if dyads were correctly diagnosing all eight patients on their first attempt of the task.

Overall, results showed that though feedback influenced groups' perceptions of how well they did on the task, it had little to no impact on group performance, collective efficacy, group cohesiveness, group goals, or strategies. On the other hand, results showed a significant Time $\mathrm{x}$ Coaching interaction predicting group performance. However, these results emerged due to unexplained differences on Task 1 between the three coaching conditions, namely the "coaching in the middle" and "no coaching" conditions. The Time $\mathrm{x}$ Coaching interactions predicting group cohesiveness and group goals were significant, as discussed later in more detail. Collective efficacy was positively related to group goals and group cohesiveness. Furthermore, collective efficacy was positively related to group performance such that group performance influenced the team's collective efficacy. Most promising, however, were the significant effects of team coaching on strategies. Coaching in the middle led to the greatest amount of strategy 
improvement, and overall, groups who shared all of the symptoms outperformed those who only shared a few of the symptoms.

Reviewing the predictions and subsequent analyses, some interesting results emerged. Overall, dyads performed better on the second attempt of the task than on the first. An improvement in performance between the two tasks was expected since the dyads would be more familiar with the task on the second attempt. In addition, the Time $\mathrm{x}$ Coaching interaction predicting group performance was significant, suggesting that the relationship between groups' performance on the first and second attempts of the task depended on the coaching condition-no coaching, a prior coaching or coaching in the middle. However, this is not the case. These results emerged primarily due to the "coaching in the middle" groups who had an early poor performance and a superior performance relative to the other two conditions on Task 2. Thus, random assignment was ineffective.

Although not predicted, I also found significant Time x Coaching interactions predicting group cohesiveness and group goals. The analyses investigating the Time x Coaching interaction predicting group cohesiveness showed that all three groups increased in group cohesiveness over time. However, groups who received coaching in the middle appeared to score lowest on group cohesiveness at Time 1 and Time 2 compared with groups in the "no coaching" or "a priori coaching" conditions. Once again, it seems groups who received coaching in the middle started out with lower cohesion than groups in the other conditions. Groups in the "a priori coaching" condition scored highest on cohesiveness throughout the experiment which suggests that a priori 
team coaching (though consultative) may lead to higher levels of group cohesiveness. The analyses investigating the Time $\mathrm{x}$ Coaching interaction predicting group goals showed that, for all three groups, group goals decreased over time. All groups started with comparable goals at Time 1, but the groups differ more at Time 2. The "no coaching" and "a priori coaching" conditions showed a similar decrease in goals over time with the "no coaching" condition posting slightly higher goals compared with the "a priori coaching" condition. Contrary to expectations, the "coaching in the middle" condition showed the sharpest decrease in goals over time. It is possible that team coaching in the middle made groups more realistic with regard to setting achievable goals.

I expected that collective efficacy, group goals, and group cohesiveness would be highly correlated with each other. Results indicated that collective efficacy at Time 1 and Time 2 was positively correlated with group goal 1 and group goal 2. In other words, the extent to which the group expected to perform well on the task was significantly correlated with the goal they set for their group. In addition, collective efficacy at Time 1, 2, and 3 was positively correlated with group cohesiveness at Time 1, 2, and 3. This suggests that the greater the belief that the group can perform the task, the greater the feeling of cohesiveness within the group and vice versa. Hypothesis $2 \mathrm{~A}$ states that collective efficacy, group goals and group cohesiveness would be positively correlated to group performance. Results demonstrated that collective efficacy at Time 2 was positively correlated with group performance on the first attempt, $r=.29$, and collective efficacy at Time 3 was positively correlated with group performance on the second attempt, $r=.63$. These results suggest that instead of collective efficacy influencing performance, group 
performance influenced collective efficacy. In other words, when a group felt they did well on the first attempt, collective efficacy increased. Similarly, when a group felt they performed poorly on the first attempt, collective efficacy subsequently decreased.

Finally, team coaching had a significant effect on strategy improvement or maintenance, but only between Task 1 and Task 2 . This suggests that coaching led to changes in strategies. Specifically, team coaching in the middle led to improvements in strategies where teams began to share symptoms with each other. Team coaching encouraged groups to approach the task in a different manner. Further analyses revealed that strategy improvement/maintenance did not lead to better group performance, which could be due to the overwhelming complexity of the task. It could also be due to groups not sharing all of the symptoms. When the two dominant strategies - split it up by sets or work together-were compared, groups who split it up by sets outperformed those who worked together. This is counterintuitive. However, when the performance of groups who shared only a few of the symptoms was compared with the performance of groups who shared all of the symptoms, the latter outperformed the former.

In general, the coaching was effective such that the groups listened to the team performance tips and incorporated them into their strategies for approaching the task. However, the optimal strategy did not lead to better performance. For one, the groups may have performed better had they shared all of the symptoms rather than just a few. In addition, the optimal strategy slowed groups down. During pilot testing, some groups were trained on how exactly to approach the task. They were trained on the predicted optimal strategy of sharing all the symptoms. When given explicit instructions, these 
groups were able to correctly and consistently diagnose at least 5 or 6 out of 8 patients and sometimes scored as high as 7 out of 8 patients. These pilot groups outperformed groups in the actual study who split it up by sets. This suggests that sharing symptoms was the optimal strategy, but the groups were not practiced enough to use it correctly. It also suggests that the team performance tips were not explicit enough.

Some of the expected results emerged, but overall, the findings were weak. It is possible that the task was too difficult, which could attenuate the effects of team coaching and feedback on group performance. Some of the groups were able to accurately diagnose 7 out of the 8 patients, but none diagnosed the full set of patients. Another possible explanation for the lack of significant interactions could be due to weak manipulations of team coaching and feedback. For the team coaching manipulation, experimenters read team performance tips out loud while the participants followed along. Though the team performance tips were identical across groups who received any kind of coaching, the experimenters could have read them differently and the dyads could have received them differently. Also important to mention, team performance tips were meant to guide the groups to think about the task differently. They were not meant to be explicit instructions. However, if the team performance tips were made a bit more explicit, it may have influenced team performance to a greater extent.

It is also possible that some participants did not pay attention to the team performance tips. However, the analyses on strategy change suggested that groups did listen to the team performance tips, but a change in strategy may have slowed them down. It is possible that a third round of the task would have shown differences in performance 
between groups who split it up by sets and those who worked together and shared all the symptoms. Future research could address this limitation. As for the feedback manipulation, it may have differed depending on which experimenter delivered it. There were a handful of experimenters who ran this study, and some may have provided more convincing positive or negative feedback compared with others.

Though the overall findings were not particularly enlightening, past research has demonstrated that team coaching and performance feedback, separately, impact group performance. However, more research is still needed on when and how team coaching affects performance, and how it also may affect collective efficacy and cohesion. In this study, simple effects tests showed that the "coaching in the middle" groups had slightly higher effect sizes than "a priori coaching" groups, although this was due to the former's early poor performance and later superior performance compared with the other conditions. Thus, the failure of random assignment to produce equivalent groups across the coaching manipulation makes drawing conclusions from these data very difficult. It may also be worthwhile to look at different tasks where different types of coaching would be relevant. In addition, further work addressing the relationships between coaching, collective efficacy, and group cohesion would aid in our understanding of how team coaching works. Given that teams are now a basic component of most organizations, additional information on how organizations can improve team performance would be beneficial to both organizations and the societies in which they exist. 
APPENDIX A:

TEAM PERFORMANCE TIPS 
Task teams that perform optimally are effective for a variety of reasons. For one, they know how to manage their time such that they stay on track regarding deadlines. For example, remember that you only have five minutes and shouldn't spend too much time on any one part of the task. They also find ways to be quick, yet effective. For example, they pay attention to the most important information to save time. Another thing that optimal task teams do is collaborate with their team members regarding the task at hand. Before starting on the next phase of the task, think about how you can coordinate your efforts to make sure all the information is available to both team members to make accurate decisions. 
APPENDIX B:

COLLECTIVE EFFICACY AND

GROUP COHESIVENESS QUESTIONNAIRES 


\section{Collective-Efficacy}

1. My team can find solutions to problems with its performance.

2. This team can pull itself out of a slump.

3. We believe that failure will make our team try harder.

4. My team member goes above and beyond the call of duty.

5. My team member works hard to complete the task.

6. My team has the skills necessary to do well at this task.

\section{Group Cohesiveness}

1. I like my team member.

2. I like being a member in this team.

3. I feel I am an important member of this team.

4. My team member likes me. 
APPENDIX C:

VIDEO CODING TEMPLATE

FOR TEAM COACHING STUDY 
Group \#

\section{Round 1: First attempt at the task}

What strategy does the group use to approach the first attempt of the task?

$\begin{array}{lllll}1 & 2 & 3 & 4 & 5\end{array}$

$1=$ split it up by sets

$2=$ work through each patient together but do not share all of the symptoms

$3=$ work through each patient together and share all the symptoms

$4=$ one person reads the symptoms and the other person checks the diagnoses packet

$5=$ other

Does the strategy change during the first attempt at the task?

Y

$\mathrm{N}$

$\begin{array}{lllllll}\text { What does it change to? } & 1 & 2 & 3 & 4 & 5\end{array}$

\section{Round 2: Second attempt at the task}

What strategy does the group use to approach the second attempt of the task?

$\begin{array}{lllll}1 & 2 & 3 & 4 & 5\end{array}$

Does the strategy change during the first attempt at the task?

Y

$\mathrm{N}$

$\begin{array}{lllllll}\text { What does it change to? } & 1 & 2 & 3 & 4 & 5\end{array}$

\section{Comments:}




\section{REFERENCES}

Baker, D. F. (2001). The development of collective efficacy in small task groups. Small Group Research, 32, 451-474.

Balcazar, E., Hopkins, B. L., \& Suarez, Y. (1985). A critical, objective review of performance feedback. Journal of Organizational Behavior Management, 7, $65-89$.

Bandura, A. (1982). Self-efficacy mechanism in human agency. American Psychologist, $37,122-147$.

Bandura, A. (1986). Social foundations of thought and action: A social cognitive theory. Englewood Cliffs, NJ: Prentice Hall.

Bandura, A. (2000). Exercise of human agency through collective efficacy. Current Directions in Psychological Science, 9, 75-78.

Bandura, A., \& Cervone, D. (1983). Self-evaluative and self-efficacy mechanisms governing the motivational effects of goal systems. Journal of Personality and Social Psychology, 45, 1017-1028.

Bandura, A., \& Cervone, D. (1986). Differential engagement of self-reactive influences in cognitive motivation. Organizational Behavior and Human Decision Processes, $38,92-113$.

Bettenhausen, K., \&Murnighan, J. K. (1985). The emergence of norms in competitive decision making groups. Administrative Science Quarterly, 30, 350-372.

Blickensderfer, E., Cannon-Bowers, J. A., \& Salas, E. (1997). Training teams to self correct: An empirical investigation. Paper presented at the annual meeting of the Society for Industrial and Organizational Psychology, St. Louis.

Carron, A. V., Brawley, L. R. and Widmeyer, W. N. (1998). Measurement of cohesion in sport and exercise. In J. L. Duda (Ed.), Advances in Sport and Exercise Psychology Measurement (pp. 213-226). Morgantown, WV: Fitness Information Technology. 
Carron, A. V., Bray, S. R., \& Eys, M. A. (2002). Team cohesion and team success in sport. Journal of Sports Sciences, 20, 119-126.

Choi, H. S., \& Levine, J. M. (2004). Minority influence in work teams: The impact of newcomers. Journal of Experimental Social Psychology, 40, 273-280.

De Cremer, C., \& Dijk, E. (2002). Reactions to group success and failure as a function of identification level: a test of the goal transformation hypothesis in social dilemmas. Journal of Experimental Social Psychology, 38, 435-442.

Ellis, S., Mendel, R., Nir, M., \& Davidi, I. (2002). After-event reviews: Drawing lessons from successful vs. failed experience. Working paper, Recanati Graduate School of Business Administration, Tel Aviv University, Tel Aviv.

Feltz, D. L., Lirgg, C. D. (1998). Perceived team and player efficacy in hockey. Journal of Applied Psychology, 83, 557-564.

Fiske, S. T., \& Taylor, S. E. (1984). Social cognition. Reading, MA: Addison-Wesley.

Gersick, C. J. G. (1988). Time and transition in work teams: Toward a new model of group development. Academy of Management Journal, 31, 9-41.

Gersick, C. J. G. (1989). Marking time: Predictable transitions in task groups. Academy of Management Journal, 32, 274-309.

Gist, M. E. (1987). Self-efficacy: Implications for organizational behavior and human resource management. Academy of Management Review, 12, 472-485.

Hackman, J. R., \& Morris, C. G. (1975). Group tasks, group interaction process, and group performance effectiveness: A review and proposed integration. In L. Berkowitz (Ed.), Advances in experimental social psychology (pp. 45-99). New York: Academic Press.

Hackman, J. R., \& Wageman, R. (2005). A theory of team coaching. Academy of Management Review, 30, 269-287.

Hackman, J. R., \& Walton, R. E. (1986). Leading groups in organizationas. In P. S. Goodman (Ed.), Designing effective work groups (pp. 72-119). San Francisco: Jossey-Bass. 
Haslam, S. A., Wegge, J., \& Postmes, T. (2009). Are we on a learning curve or a treadmill? The benefits of participative group goal setting become apparent as tasks become increasingly challenging over time, European Journal of Social Psychology, 39, 430-446.

Jung, D. I., \& Sosik, J. J. (2002). Transformational leadership in work groups: The role of empowerment, cohesiveness, and collective-efficacy on perceived group performance. Small Group Research, 33, 313.

Kernaghan, J. A., \& Cooke, R. A. (1990). Teamwork in panning innovative projects: Improving group performance by rational and interpersonal interventions in group process. IEEE Transactions on Engineering management, 37, 109-116.

Klein, H. J., \& Mulvey, P. W. (1995).Two investigations of the relationships among group goals, goal commitment, cohesion and performance. Organizational Behavior and Human Decision Processes, 61, 44-53.

Kluger, A. N., \& DeNisi, A. (1996). The effects of feedback interventions on performance: A historical review, a meta-analysis, and a preliminary feedback intervention theory. Psychological Bulletin, 119, 254-284.

Kozlowski, S. W. J., Gully, S. M., Salas, E, \& Cannon-Bowers, J. A. (1996). Team leadership and development: Theory, principles, and guidelines for training leaders and teams. In M. Beyerlein, D. Johnson, \& S. Beyerlein (Eds.), Advances in interdisciplinary studies of work teams: Team leadership (pp. 251-289). Greenwich, CT: JAI Press.

Locke, E. A., \& Latham, G. P. (1990). A theory of goal setting and task performance. Englewood Cliffs, NJ: Prentice-Hall.

Locke, E. A., \& Latham, G. P. (2006). New directions in goal-setting theory. Current Directions in Psychological Science, 15, 265-268.

Mitchell, T. R., \& Silver, W. S. (1990). Individual and group goals when workers are interdependent: Effects on task strategies and performance, Journal of Applied Psychology, 75, 185-193.

Mullen, B., \& Copper, C. (1994). The relation between group cohesiveness and performance: An integration. Psychological Bulletin, 115, 210-227.

Mulvey, P. W., \& Klein, H. J. (1998). The impact of perceived loafing and collective efficacy on group goal processes and group performance. Organizational Behavior and Human Decision Processes, 74, 62-87. 
Prussia, G. E., \& Kinicki, A. J. (1996). A motivational investigation of group effectiveness using social-cognitive theory. Journal of Applied Psychology, 81, 187-198.

Snyder, C. R., Lassegard, M., \& Ford, C. E. (1986). Distancing after group success and failure: Basking in reflected glory and cutting off reflected failure. Journal of Personality and Social Psychology, 51, 382-388.

Steiner, I. D. (1972). Group process and productivity. New York: Academic Press.

Tuckman, B. W. (1965). Developmental sequence in small groups. Psychological Bulletin, 63, 384-399.

Wageman, R., Hackman, J. R., \& Lehman, E. V. (2004). Development of the Team Diagnostic Survey. Working paper, Tuck School, Dartmouth College, Hanover, NH.

Weiner, B. (1985). “Spontaneous” causal thinking. Psychological Bulletin, 97, 74-84.

Woolley, A. W. (1998). Effects of intervention content and timing on group task performance. Journal of Applied Behavioral Science, 34, 30-49. 
VITA

Rachael Martínez was born and raised in Cincinnati, OH. Before attending Loyola University Chicago, she attended the University of Michigan, Ann Arbor, where she earned a bachelor of arts in psychology in 2008. While at Michigan, she served as the student manager for the Michigan Varsity Softball team from 2004 to 2006 and as a catcher from 2006 to 2008. During her time on the team, she earned the Academic AllBig Ten Conference and UM Athletic Academic Achievement Awards and also made the Dean's list. In addition, she worked as a research assistant for three semesters in the lab of Dr. Jennifer Crocker, a distinguished social psychologist. Her honors thesis was also under the supervision of Dr. Crocker.

At Loyola, Rachael works directly with Dr. R. Scott Tindale on various studies exploring group dynamics, specifically group decision making. She has presented a poster, and has been listed as one of the authors on other posters and presentations, at the Midwestern Psychological Conference. Additionally, she has worked on projects with organizations outside of the university including the YWCA Medical and Legal Advocacy Services and Andrew M. Hale \& Associates.

Currently, Rachael is still a Graduate Research Assistant in Dr. Tindale's lab and lives in Chicago, IL. 


\section{THESIS APPROVAL SHEET}

The thesis submitted by Rachael Martínez has been read and approved by the following committee:

R. Scott Tindale, Ph.D., Director

Professor of Social Psychology

Loyola University Chicago

Robyn Mallett, Ph.D.

Assistant Professor of Social Psychology

Loyola University Chicago

The final copies have been examined by the director of the thesis and the signature which appears below verifies the fact that any necessary changes have been incorporated and that the thesis is now given final approval by the committee with reference to content and form.

The thesis is therefore accepted in partial fulfillment of the requirements for the degree of Master of Arts.

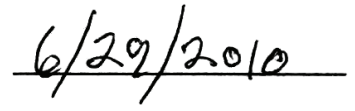

Date

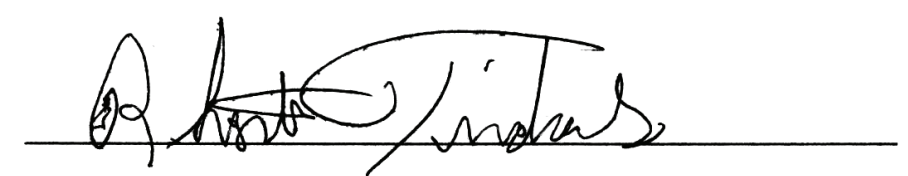

Director's Signature 
